\title{
Research on the Subject System of Freedom of Information on Agricultural Genetically Engineered
}

\author{
Huijun Chen \\ China University of Political Science and Law, Chinese National Police University, Beijing, 100088, China
}

Keywords: Subject system, Agricultural genetically engineered, Freedom of information

\begin{abstract}
Information disclosure of agricultural transgenic issues is an important part of the government information disclosure system. The publicity of agricultural GM information must be based on the perspective of globalization, the dimension of law, and the national conditions of our country. The systematic risk of such information publicity must be prevented. There are many problems in the main system of GM information disclosure in our country, such as a large number of subjects, a high level of publicity, ambiguous limits of authority of the subject and so on, which should be perfected from the above aspects.
\end{abstract}

\section{Introduction}

Transgenic technology should be one of the most pioneering biotechnologies in the 21st century, and also one of the most controversial technologies. At present, the research on the information disclosure system of agricultural GMOs in China is still in its infancy. The application of the Regulations on Information Disclosure in the field of agricultural GMOs has its particularity and should be studied independently. Research can be divided into main research, scope study, content study and relief research. This article will discuss one of the fundamental issues of agricultural transgenic information disclosure, the subject.

\section{Factors to be Considered of Agricultural Genetically Engineered in Public Research}

\subsection{Based on the Vision of Globalization.}

From the earliest cultivation of genetically modified crops in the United States to the present, most countries are developing or applying genetically modified technologies. Obviously, the problem of genetically modified crops is not only a problem of a single country, but also a problem of globalization. From the present research results, we cannot agree with the safety of transgene. However, for most of the countries that have conducted research and application of GM technology, although they are more cautious about the issue of GM, they are all actively promoting and improving the technology of GM. The fundamental reason is that this technology is undoubtedly an optimal choice to solve the contradiction between the shortage of human resources in the future and the increasing population demand. Gene modification technology can also meet the needs of people who pursue healthier, more nutritious and safer foods. In modern society, global warming, greenhouse effect, environmental pollution, resource shortage and other issues can no longer be considered as a problem of a country or region, but a common problem facing human survival and development. Therefore, intensive development of sustainability is an important reason for various countries to choose transgenic technology.

\subsection{Based on the Dimension of Law.}

Although there are many dimensions to discuss the issue of GM, such as politics, culture, ethics, economy and environment, the law is unavoidable after all. Some scholars believe that information disclosure is a legal issue, and the subject, scope, conditions and procedures of information disclosure should be solved within the legal framework. This perspective is simply to regard the issue of 
genetically modified organisms as an independent issue. I believe that the system of agricultural GM information disclosure under the legal dimension will influence and shape the recognition of what is and what is not legal GM products. Genetically modified information disclosure is not only the need of the government ruled by law and administration by law, but also creates a specific situation. In this situation, we should actually create influential discourses such as "science", "value", "expert knowledge". That is to say, the disclosure of genetically modified information is to bring science into political process and regulatory process through legal means, so that technology itself can be properly understood. At the same time, the disclosure of genetically modified information can keep science away from politics, policies and laws, thus ensuring the integrity and integrity of science. Irrational fear and arbitrary value choice will poison proper scientific analysis. Information disclosure itself is a powerful way to exclude fear and guide value. Therefore, in this sense, the disclosure of GM information should go beyond its own significance as a tool theory.

\subsection{Based on the Situation of China.}

Some experts argue that in the past 5 years, the attitude of Chinese public towards GM has shifted from basic neutrality to negation. In fact, most people do not know much about GM technology and its advantages and disadvantages. All knowledge acquisition is fragmented, mostly from media coverage and publicity. Therefore, if agricultural GM products want to be recognized by the whole society, scientists as experts have an unshirkable responsibility. However, in reality, expert opinions have not been effectively disseminated. First, the channels of dissemination are limited. Second, the scope of dissemination is severely limited. More sceptics believe that expert positions have been assimilated by commercial interests. The average per capita cultivated land in China is only $40 \%$ of the world average. In the next 20 years, China needs to increase $30 \%$ to $50 \%$ of its grain output to meet the growing demand of the population. This has also led to public doubts about whether to solve the problem of food and clothing, the government insists on the safety of genetically modified organisms. In addition, some well-known people's surveys (such as Cui Yongyuan's on-the-spot research on GM in the United States) and remarks, though not conclusive on the issue of GM, still arouse speculation and distrust on GM issues. According to psychological research, it is generally believed that there is no need to investigate and discuss the facts that are not controversial. The discussion is precisely about the uncertainty of the problem.

\subsection{To Prevent Systemic Risk of Such Information Disclosure.}

Agricultural transgenic information disclosure is one of the ways that the government regulates risks. However, the regulatory priorities set by administrative regulatory agencies are often not carefully studied by independent experts, but usually consider maximizing benefits at the lowest cost. In the priority and agenda setting of GM information disclosure, the scope of information disclosure is often driven by public fears, politics, conventions and even contingency, which makes it impossible for experts to think that the most important thing may not be on the agenda of regulatory bodies. It can be said that the core issue of information disclosure standards: what is acceptable risk, has an important social and political side. To embody a certain balance in information disclosure itself, we need to consider many factors in detail when formulating relevant systems to prevent other risks that may arise from a certain open information. Bertalanffy defined the system as "a complex of elements of interaction". The disclosure of agricultural GM information should consider specific factual conditions. At the same time, different specific issues of information disclosure will lead to completely different social and political concerns. Therefore, when considering the disclosure of relevant information, we should have a systematic awareness of prevention, and try our best to avoid other risks arising from the disclosure of one piece of information. 


\section{Subject and Its Power of Freedom of Information on Agricultural Genetically Engineered at this Stage}

\subsection{Freedom of Information on Agricultural Genetically Engineered in China.}

The subject of agricultural GM information disclosure is inseparable from the responsibilities and powers of various departments themselves. At present, the regulation system of agricultural GMOs in China is mainly based on the administrative departments of agriculture as the core, and the management system of division of labor and cooperation of other departments. The existing regulatory agencies of GM food safety in China can be divided into three levels. The first level is a joint inter-ministerial meeting composed of the Ministry of Agriculture, the National Development and Reform Commission, the Ministry of Science and Technology, the Ministry of Health, the Ministry of Commerce, the General Administration of Quality Supervision, Inspection and Quarantine and the Ministry of Environmental Protection. Major issues in the study and coordination. Following the promulgation of the Food Safety Law, the Food Safety Committee, as a high-level deliberative and coordinating body of the national food safety work, was established. The main responsibilities of the Food Safety Committee are to study, deploy and guide food safety work as a whole; to formulate major policies and measures for food safety supervision; and to implement the responsibility of food safety supervision. In the regulation system of GM food safety, the status of the agency should be explored. The second level is that the ministries and commissions under the State Council exercise the regulatory power of genetically modified organisms and food safety within their respective functions. The third level is that the administrative departments of health, agriculture, quality supervision, industry and commerce at or above the county level are responsible for the supervision of genetically modified organisms and food safety in the region.

\subsection{Freedom of Information on Agricultural Genetically Engineered in America.}

In the United States, GM regulation belongs to different departments, so its information disclosure is carried out by different regulators within their respective jurisdictions. The FDA, USDA and EPA are responsible for testing, evaluating and supervising GM food safety and implementing the basic regulatory policies. The three departments work together to ensure the safety of GM foods and promote the research and application of transgenic technology. Among them, FDA's Food Safety and Applied Nutrition Center is responsible for regulating the safety of food and food additives, managing food labeling and ensuring the food safety of genetically modified proteins. USDA ensures the safe cultivation of genetically modified organisms and the safety of meat, poultry and egg products. It has the Animal and Plant Quarantine Bureau (APHIS) and the Food Safety and Inspection Bureau (FSIS). APHIS manages GM crop cultivation, examines and approves field trials of GM microorganisms and registers veterinary bioengineering products, and FSIS manages the safety and health effects of meat, poultry and egg products on consumers. EPA is responsible for managing pesticides, analyzing the effects of crop pesticides on human body and environment, and stipulating the maximum residues of pesticides in food. The regulatory scope of each department is determined by the ultimate use of GM food. A product may involve regulatory coordination and coordination of multiple departments. However, according to the relevant data, the United States currently has an independent website on agricultural GM information disclosure, but most of the information is summarized in the United States FDA website. That is to say, the basic information about the publication of GM information in agriculture from other departments can be found on the FDA website, or the website of the Ministry of Agriculture can provide website links or special mailboxes for the public to find further details. 


\section{Main Problems and Reform Directions of Subject System of Freedom of Information on}

Agricultural Genetically Engineered in Current China

\subsection{The Subjects of Freedom of Information on Agricultural Genetically Engineered Are Various and Freedom of Information is Limited to the Subject at High Level.}

The government, as an open institution of agricultural genetically modified information, is not independent and single, but an organic whole which is closely related both horizontally and vertically. Horizontally, it includes not only the State Council as a leading body, but also different departments such as the Ministry of Agriculture, the Health Planning Commission, the State Administration of Quality Supervision, Inspection and Quarantine, and so on. The joint meeting of 12 departments, including agriculture, science and technology, environmental protection, health, quality inspection and food and drug administration, also includes local departments of agricultural health and environmental protection at all levels. There are many subjects and problems involved in the disclosure of agricultural GM information. Under the joint inter-ministerial meeting, there is no uniform system of information disclosure to the outside world. Instead, ministries and commissions continue to exercise their respective functions and powers of information disclosure. This way of information disclosure is similar to that of the United States, but the difference is that the United States will explicitly prompt other agencies to provide information links or mailboxes on their information disclosure websites. If so, it will largely eliminate public doubts and simplify the process of public understanding of information.

\subsection{The authority boundary of Subject of Freedom of Information on Agricultural Genetically Engineered Is Blurred.}

Through the investigation and collation of the initiative disclosure of agricultural genetically modified information on the websites of relevant ministries and commissions of the Ministry of Agriculture, the Health Planning Commission and other joint meetings of agricultural genetically modified ministries, I summarized the functions and powers of relevant ministries and commissions in the field of genetically modified supervision. The result is shown in the following table:

Table 1 Results

\begin{tabular}{|c|c|c|c|c|}
\hline $\begin{array}{l}\text { Transgenic } \\
\text { regulatory } \\
\text { function }\end{array}$ & $\begin{array}{l}\text { Formulate laws and } \\
\text { regulations concerning } \\
\text { genetically modified food } \\
\text { safety management. } \\
\text { The safety assessment } \\
\text { standards and approval } \\
\text { procedures for genetically } \\
\text { modified organisms } \\
\text { should be formulated. } \\
\text { To be responsible for the } \\
\text { approval, supervision and } \\
\text { management of the } \\
\text { labeling of genetically } \\
\text { modified foods in the } \\
\text { whole country. }\end{array}$ & $\begin{array}{l}\text { To formulate and promulgate } \\
\text { rules and standards for the } \\
\text { evaluation of food safety and } \\
\text { nutritional quality of } \\
\text { genetically modified foods. } \\
\text { The production and import of } \\
\text { genetically modified food } \\
\text { shall be examined and } \\
\text { approved for safety, and the } \\
\text { production and operation } \\
\text { organizations shall be } \\
\text { regularly or irregularly } \\
\text { supervised and spot checked. } \\
\text { Labeling management of } \\
\text { genetically modified food } \\
\text { products }\end{array}$ & $\begin{array}{l}\text { Responsible } \\
\text { for the safety } \\
\text { assessment of } \\
\text { genetically } \\
\text { modified } \\
\text { organisms, } \\
\text { involving the } \\
\text { assessment } \\
\text { and } \\
\text { management of } \\
\text { environmental } \\
\text { pollution. }\end{array}$ & $\begin{array}{l}\text { Supervise } \\
\text { and inspect } \\
\text { the safety of } \\
\text { agro based } \\
\text { foods. }\end{array}$ \\
\hline
\end{tabular}

The ministries and commissions of the State Council at the second level of government regulation of agricultural GMOs play a connecting role in the supervision and information disclosure of agricultural GMOs. However, a careful analysis of the functions and powers of ministries and commissions in the publicity of agricultural genetically modified information is vague. Genetically modified organisms (GMOs) involve many functional departments in a series of processes, such as 
cultivation, cultivation, harvesting, processing and trafficking.

The author inquired about the agricultural GM information that the four ministries and commissions had voluntarily disclosed, and found that most of them were based on the government's work dynamics and policies and regulations. Through sorting out the agricultural genetically modified information, it is found that most of the work dynamics in the agricultural genetically modified information published by the four ministries are the openness of leadership speech and the change of institutional functions. Most of the active publication of genetically modified policies and regulations emphasizes the supervision of the circulation of genetically modified products, and pays more attention to the public. The policies and regulations of genetically modified products in production, experiment, cultivation, processing and other fields are rarely reflected. By comparing the annual report data of information disclosure of four ministries and commissions, I find that there is a reverse relationship between the amount of applications for information disclosure and information disclosure. It clearly shows that there is a reverse relationship between the degree of information disclosure and the application of information disclosure. Whether this reflects to a certain extent that the public feel deeply that the agricultural GM information cannot be obtained through the initiative of government departments, but can only alleviate the imbalance in the grasp of agricultural GM information with the GM government regulatory authorities by applying for publicity.

The third level of agricultural GM government regulatory agencies is the local agriculture, health and environmental protection departments, which are the front positions of agricultural GM. By investigating and sorting out the websites of the three-level agricultural departments in Beijing, I conclude the functions of the three-level agricultural departments in the publicity of agricultural GM information. The Ministry of Agriculture, as the second level of GM supervision, is the overall guidance and management of the national agricultural sector.

In the survey of the agricultural department websites in other districts of Beijing, I found that there are no agricultural departments corresponding to Beijing Agricultural Bureau in some non-agricultural planting areas. Are there any other departments to supervise the genetically modified products appearing in these areas? If not, there will be regulatory vacancies. This also reflects the one-sided regulation of GM products from one aspect. Only through the continuous improvement of local GM regulatory departments at all levels and the supervision and management of GM planting, experiment, production and operation in the region according to their responsibilities, can the public's awareness of agricultural GM be guaranteed to the maximum extent, the public's doubts and fears about agricultural GM be eliminated, and social production be guaranteed. The orderly, healthy and environmental development of life.

\section{References}

[1] Ren Zhentao, Shen Wenjing, Liu Biao. Effects of Transgenic Maize on Biodiversity of Arthropod Communities in the Fields [J]. Scientia Agricultura Sinica, 2017, 50(12): 2315-2325.

[2] Wang Mingyuan, Jin Feng. Environmental Justice in the Context of Scientific Uncertainty: On the Safety of Genetically Modified Organisms [J]. Social Sciences in China, 2018, 39(2): 58-76.

[3] Zhao Xia, Wang Yuguang. A Bibliometrical Analysis of Genetically Modified Food Safety Research [J]. Journal of Library and Information Sciences in Agriculture, 2014, 26(4): 45-49.

[4] Maarten J.Chrispeels. Global production and consumption of genetically engineered crops [J]. Journal of Huazhong Agricultural University, 2014, 33(6): 120-132. 